\title{
Boric Acid Corrosion of Concrete Rebar
}

\author{
R.T. Pabalan ${ }^{1}$, L. Yang ${ }^{2}$, and K.-T. Chiang ${ }^{3}$ \\ ${ }^{1}$ Center for Nuclear Waste Regulatory Analyses, San Antonio, Texas, U.S.A. \\ ${ }^{2}$ Corr Instruments, LLC, San Antonio, Texas, U.S.A. \\ ${ }^{3}$ Southwest Research Institute ${ }^{\circledR}$, San Antonio, Texas, U.S.A.
}

\begin{abstract}
Borated water leakage through spent fuel pools (SFPs) at pressurized water reactors is a concern because it could cause corrosion of reinforcement steel in the concrete structure and compromise the integrity of the structure. Because corrosion rate of carbon steel in concrete in the presence of boric acid is lacking in published literature and available data are equivocal on the effect of boric acid on rebar corrosion, corrosion rate measurements were conducted in this study using several test methods. Rebar corrosion rates were measured in (i) borated water flowing in a simulated concrete crack, (ii) borated water flowing over a concrete surface, (iii) borated water that has reacted with concrete, and (iv) 2,400 ppm boric acid solutions with $\mathrm{pH}$ adjusted to a range of 6.0 to 7.7. The corrosion rates were measured using coupled multielectrode array sensor (CMAS) and linear polarization resistance (LPR) probes, both made using carbon steel. The results indicate that rebar corrosion rates are low $(\sim 1 \mu \mathrm{m} / \mathrm{yr}$ or less) when the solution $\mathrm{pH}$ is $\sim 7.1$ or higher. Below $\mathrm{pH} \sim 7.1$, the corrosion rate increases with decreasing $\mathrm{pH}$ and can reach $\sim 100 \mu \mathrm{m} / \mathrm{yr}$ in solutions with $\mathrm{pH}$ less than $\sim 6.7$. The threshold $\mathrm{pH}$ for carbon steel corrosion in borated solution is between 6.8 and 7.3.
\end{abstract}

\section{Introduction}

Spent fuel pools (SFPs) at pressurized water reactors are seismically qualified structures that contain borated water, maintain spent fuel temperatures, and provide radiation shielding. SFPs typically are lined with stainless steel plates on the inner surface of reinforced concrete structures. There is a concern that long-term leakage of borated water through the SFP liners, reactor cavities, and fuel transfer canals at pressurized water reactors could degrade the concrete support structures and associated reinforcement steel [1]. The borated water could reduce the inherent alkaline environment of the concrete, expose the rebar to mildly acidic solutions, and initiate rebar corrosion. The corrosion products could exert pressure on the surrounding concrete, cause cracks to form or propagate, and potentially compromise the structural integrity of the SFP concrete structure or cause unmonitored releases of contaminated water to the environment.

There is a lack of data in published literature on corrosion rates of carbon steel in concrete in the presence of boric acid and available data are equivocal on the effect of boric acid on rebar corrosion [2]. For example, a long-term (2-year) investigation of rebar corrosion in reinforced concrete cracks penetrated by distilled water and boric acid solutions with $\mathrm{pH} 5.2$ and 6.1 indicated a higher degree of corrosion in cracks with wider apertures and/or penetrated by water with lower $\mathrm{pH}$ [3]. No 
significant reduction in reinforcement cross section was observed in that study after 2 years, although the authors acknowledged that increased corrosion is expected at longer periods, particularly for tests using wider crack widths and lower solution $\mathrm{pH}$ [3]. On the other hand, a study that measured the weight loss of rebar immersed in boric acid solutions [2,200, 8,000, and $\left.30,000 \mathrm{ppm} \mathrm{B}(\mathrm{OH})_{3}\right]$ and rebar exposed to the natural environment indicated that there is no clear relationship between boric acid concentration and weight loss and that boric acid has no significant effect on rebar corrosion [4]. In addition, a study to support a U.S. patent indicated that boron containing compounds, including boric acid, are effective inhibitors of chloride-induced corrosion of steel in reinforced concrete structures [5].

In this study, corrosion experiments were performed to determine corrosion rates of carbon steel in concrete in the presence of boric acid.

\section{Experimental Procedure}

Rebar corrosion rates were measured in borated water flowing in a simulated concrete crack. The concrete crack was simulated using two $60 \times 60 \times 15 \mathrm{~cm}$ blocks of concrete separated by a distance of $\sim 1.0 \mathrm{~mm}$ (Figure 1). The sides and bottoms of the blocks were lined with plexiglass. A plexiglass box serving as borated (2,400 ppm B) water reservoir was placed over the simulated crack at the top of the two blocks. All surfaces of the concrete in contact with plexiglass were sealed with silicone.

To measure the corrosion rate, three pairs of coupled multielectrode array sensor (CMAS) and linear polarization resistance (LPR) probes were embedded in the concrete during the pouring stage at the locations shown in Figure 1. Two pairs of CMAS and LPR probes were arranged such that the sensing electrode surfaces were exposed to borated water in the simulated concrete crack. One of these two pairs of probes was placed high in the concrete block such that the sensing electrode surfaces were contacted by relatively fresh borated water and the other pair was placed close to the bottom of the concrete block so the sensing electrode surfaces were contacted by borated water that has reacted with the concrete. The third pair of the CMAS and LPR probes was placed such that their sensing electrode surfaces are $5.08 \mathrm{~cm}$ below the concrete surface to provide the baseline

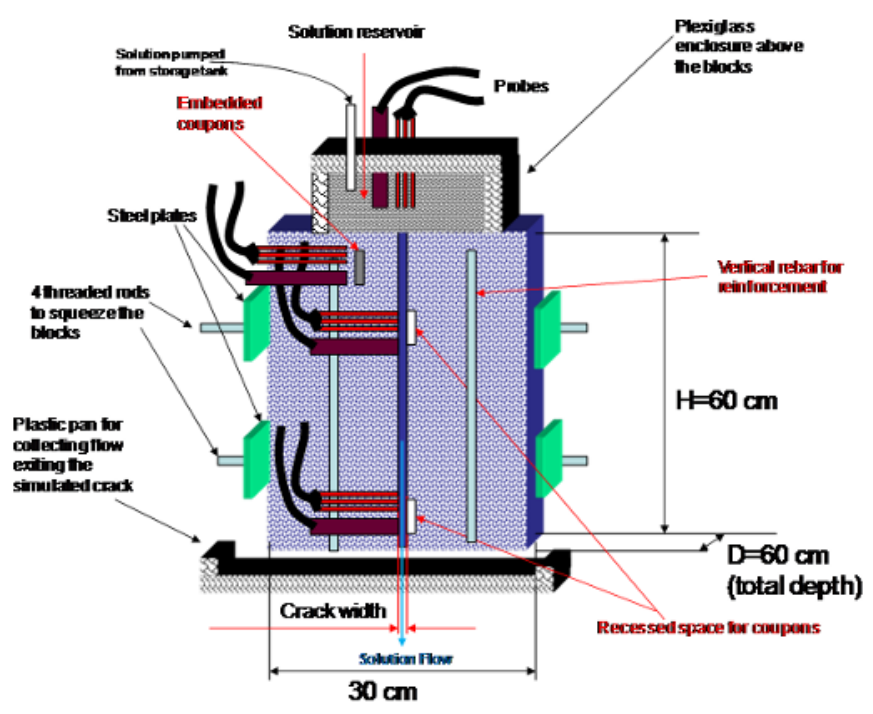

(a)

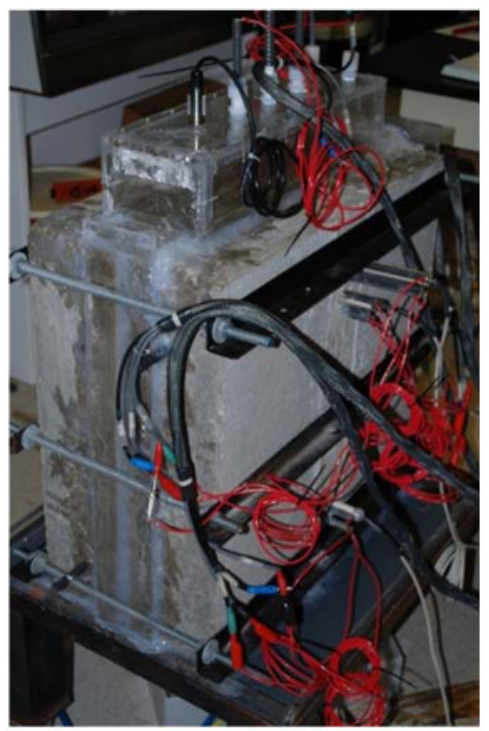

(b)

Fig. 1. (a) Schematic and (b) picture of experimental setup showing placement of CMAS and LPR probes and coupons machined from rebars 
corrosion rate for rebars in concrete. A fourth pair of CMAS and LPR probes was immersed in the borated water reservoir above the concrete blocks.

The CMAS probes were fabricated with nine 1-mm diameter, carbon steel (Type 1018) electrodes that were embedded in an epoxy insulator. The LPR electrodes were made from carbon steel rebar (6.4- to 9.5-mm diameter) and the electrode side surface was coated with epoxy such that the active electrode surface area was restricted to the electrode tip cross sectional area. For both the CMAS and the LPR probes, only the electrode sensing tips were polished and exposed to the solution. Identical electrodes were used as the working, counter, and reference electrodes for LPR measurements. A CMAS measuring system described in [6] was used with the CMAS probes. A multichannel potentiostat was used to automatically conduct the polarization on the LPR electrodes for corrosion rate measurements and to measure the open circuit potential of the electrodes between the polarization measurements. The polarization measurements were conducted every 3 to 6 hours with a three-electrode configuration. The polarization potential range was -15 to $+15 \mathrm{mV}$ (versus open circuit potential) and the potential scan rate was $0.1667 \mathrm{mV} / \mathrm{sec}$.

Coupons machined from rebars also were embedded near each pair of corrosion probes along the simulated concrete crack and were retrieved after termination of the experiment. The weight loss data on these coupons were used to verify the general corrosion rates measured by the LPR probes.

The borated water flow rate through the simulated crack was adjusted using a control valve at the bottom of the block and the amount of solution in the plexiglass reservoir was maintained as constant as possible by pumping replacement solution from a plastic storage tank. At sufficiently low flow rates (less than $\sim 4 \mathrm{~mL} / \mathrm{min}$ ), continuous solution flow through the simulated crack was allowed and corrosion data was acquired continuously using the data acquisition system. In addition, the solution exiting the simulated crack was collected for a supplementary corrosion test described in the next paragraph.

Because the test results indicated that solution was channeling in the simulated concrete crack, the concrete block assembly was disassembled and three supplementary tests were conducted to measure the corrosion rates in borated waters that have reacted with concrete and to determine the threshold $\mathrm{pH}$ below which rebar corrosion is negligible. In supplementary test 1 , the concrete block with embedded CMAS probes was inclined and borated $(2,400 \mathrm{ppm} \mathrm{B})$ water was dripped onto its surface and allowed to flow over the two CMAS probes located along the flow path. The drip rate was maintained at $\sim 20 \mathrm{~mL} / \mathrm{min}$ and the nonuniform corrosion rates were measured using the CMAS probes. In addition, the $\mathrm{pH}$ of the solution that was flowing adjacent to the CMAS probes was measured periodically using a microflow $\mathrm{pH}$ electrode (Lazar Research Laboratories, Inc., Los Angeles, California). The $\mathrm{pH}$ of the borated water, initially 4.7 , increased as it flowed and reacted with the concrete surface, typically reaching a value of 6.5 to 6.9 near the second CMAS probe. To enable corrosion rate measurements at higher $\mathrm{pHs}$, the initial $\mathrm{pH}$ of the 2,400 ppm B solution that was dripped onto the concrete surface was adjusted to higher values by mixing to the feed solution an aliquot of simulated cement pore solution, which had the following composition [2]: $0.131 \mathrm{M} \mathrm{NaOH}, 0.320 \mathrm{M} \mathrm{KOH}, 0.0032 \mathrm{M} \mathrm{CaSO}_{4}$, and $0.032 \mathrm{M} \mathrm{Ca}(\mathrm{OH})_{2}$.

In supplementary test 2 , nonuniform corrosion rates versus time were measured using CMAS probes immersed in solutions that were collected exiting the concrete block during the simulated concrete crack experiment. The $\mathrm{pH}$ of the collected solutions also was measured.

In supplementary test 3, corrosion rates were measured using CMAS probes immersed in $2,400 \mathrm{ppm}$ B solutions with $\mathrm{pH}$ in the range 6.0 to 7.7. The $\mathrm{pH}$ of the solutions was adjusted by adding aliquots of simulated cement pore solution to the 2,400 ppm B solutions. The corrosion rates generally were monitored for at least 10 days except in high $\mathrm{pH}$ solutions where corrosion rates approached steady state values in 2-3 days.

\section{Experimental Results}

Figure 2(a) shows the uniform corrosion rates versus time measured using LPR with probe tips (i) embedded inside the concrete block, (ii) placed at the simulated crack surface near the top of the 
concrete block, (iii) placed at the simulated crack surface near the bottom of the concrete block, or (iv) immersed in the reservoir solution. The corrosion rates were derived from the measured polarization resistance using the Stern-Geary equation, as described in [2]. Although the potentiostat is capable of measuring very low current density $\left(<10^{-10} \mathrm{~A} / \mathrm{cm}^{2}\right)$, significant scattering was observed in the slopes of the potential versus current scans when the corrosion rate was less than $1 \mu \mathrm{m} / \mathrm{yr}$. Some of the slopes had negative values, which correspond to negative corrosion rates and, thus, are unreasonable. For plotting purposes, corrosion rates that are negative or less than $0.001 \mu \mathrm{m} / \mathrm{yr}$ were plotted as $0.001 \mu \mathrm{m} / \mathrm{yr}$ in Figure 2(a).

The uniform corrosion rates from all the probes in the concrete blocks were low (less than $1 \mu \mathrm{m} / \mathrm{yr}$ ). Although the corrosion rates from the probe embedded inside the concrete block appear to be lower than those from the probes installed at the simulated concrete crack, both sets of values are within measurement error. No significant corrosion rate dependence with time is evident from Figure 2(a). The corrosion rates measured with the LPR probe immersed in the borated water reservoir were between 100 and 1,450 $\mu \mathrm{m} / \mathrm{yr}$.

Figure 2(b) shows the nonuniform corrosion rate data over a 3-month period measured with the CMAS probes. The flow rates used and the corresponding $\mathrm{pH}$ of borated water exiting the simulated concrete block are tabulated in Table 1. Except for four short durations in the figure, the nonuniform corrosion rates were all less than $0.5 \mu \mathrm{m} / \mathrm{yr}$, which is the lower detection limit of the CMAS unit. Even at a high flow rate of $65 \mathrm{~mL} / \mathrm{min}$ (exit $\mathrm{pH}=6.66$ ), the corrosion rates measured with the CMAS probes were below $0.5 \mu \mathrm{m} / \mathrm{yr}$. The four instances when high nonuniform corrosion rates were observed were (i) at the start of the test during which the flow rate was not well controlled and
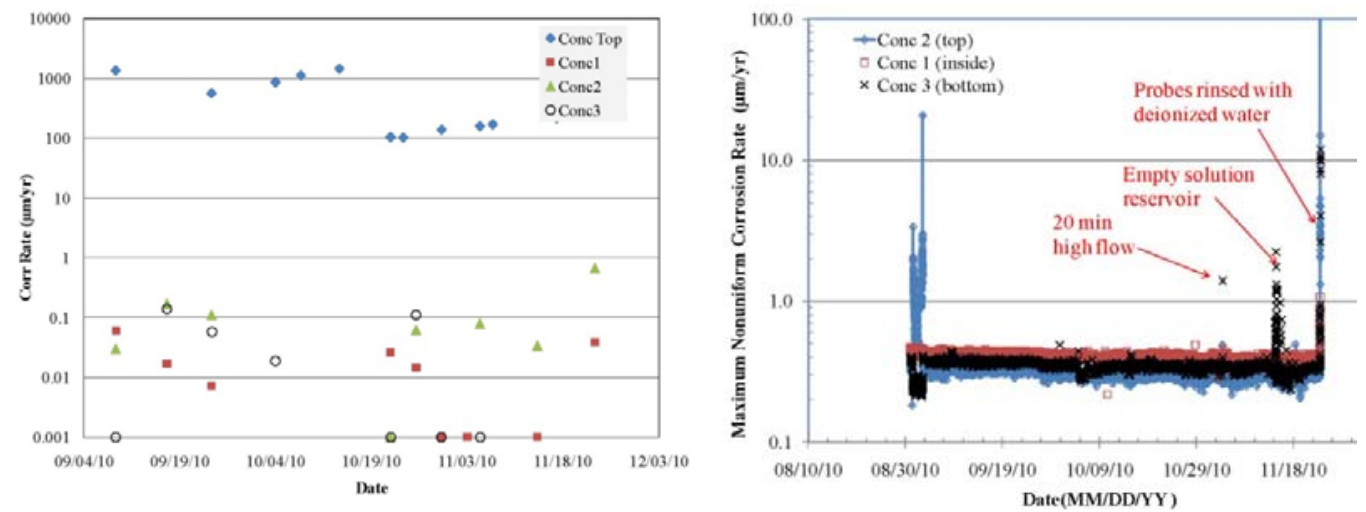

Fig. 2. (a) Uniform corrosion rates versus time measured using LPR probes and (b) nonuniform corrosion rates versus time measured using CMAS probes. Probe tips were embedded two inches below the concrete surface (Conc1); placed along the simulated concrete crack near the top of the concrete block (Conc2); placed along the simulated crack near the bottom of the concrete block (Conc3), or in the reservoir solution (Conc Top).

Table 1. Flow rate and $\mathrm{pH}$ of borated water exiting concrete block*

\begin{tabular}{|c|c|c|c|}
\hline Flow Rate (mL/min) & $\begin{array}{c}\text { pH of Solution } \\
\text { Exiting Concrete } \\
\text { Block }\end{array}$ & Flow Rate (mL/min) & $\begin{array}{c}\text { pH of Solution } \\
\text { Exiting Concrete } \\
\text { Block }\end{array}$ \\
\hline $0.75 \dagger$ & 8.2 & $8.90 \ddagger$ & 7.25 \\
\hline $1.90 \dagger$ & 7.6 & $18.7 \ddagger$ & 6.97 \\
\hline $1.60 \dagger$ & 7.52 & $17 \ddagger$ & 6.93 \\
\hline $1.33 \dagger$ & 7.43 & $65 \ddagger$ & 6.66 \\
\hline $4.20 \dagger$ & 7.36 & $1,100 \S$ & 5.92 \\
\hline $4.10 \ddagger$ & 7.32 & & \\
\hline \multicolumn{4}{|l}{} \\
*Total duration of the test is 82 days; $\dagger$ Solution flowed continuously \\
₹Solution flowed only during the day; §Solution flowed for 20 min only \\
\hline
\end{tabular}


was higher than planned; (ii) when the flow was raised to a very high rate $(1,100 \mathrm{~mL} / \mathrm{min})$ for about 20 minutes; (iii) toward the end of the experiment, when the solution reservoir was inadvertently drained; and (iv) at the termination of the test, when the concrete block was disassembled and the probes rinsed with deionized water. The sudden increase in corrosion rate observed at the end of the test is an indication that the probes responded well to changes in environment corrosivity. The low corrosion rates measured at a high flow rate of $65 \mathrm{~mL} / \mathrm{min}$ were surprising given that the solution $\mathrm{pH}$ was 6.66. The low corrosion rate is in contrast to the results of supplementary test 2 described in the next section which indicated that the measured corrosion rates were less than $1 \mu \mathrm{m} / \mathrm{yr}$ when the solution $\mathrm{pH}$ was 7.32 or higher, but greater than $30 \mu \mathrm{m} / \mathrm{yr}$ when the solution $\mathrm{pH}$ was 6.96 or lower.

The simulated concrete crack test results suggested that borated solution was channeling in the simulated crack such that low $\mathrm{pH}$ borated water was bypassing the CMAS and LPR probes. Therefore, the concrete blocks were disassembled and three supplementary tests described previously were conducted to collect additional corrosion rate data.

Figure 3 shows the disassembled blocks and the rebar coupon and corrosion probe locations on the concrete block surfaces. All the CMAS and LPR probe tips and the rebar coupons located near the top of the concrete block showed no evidence of significant corrosion. Of the four coupons located near the bottom of the block, two were corroded and the other two showed no evidence of corrosion. These observations are consistent with flow channeling of the borated water inside the simulated concrete crack. The general corrosion rates calculated from the weight loss of the two corroded rebar coupons are 5.8 and $0.9 \mu \mathrm{m} / \mathrm{yr}$.

\subsection{Supplementary test data}

Short-term data from supplementary test 1 on nonuniform corrosion rates versus time are shown in Figure 4. The corrosion rates measured with the upper CMAS probe were higher than those measured with the lower CMAS probe because the solution contacting the former had lower $\mathrm{pH}$ than that contacting the latter. Qualitatively, the data indicate that short-term $(<3$ days) corrosion rates are significant ( $\sim 10 \mu \mathrm{m} / \mathrm{yr}$ or higher) when the solution $\mathrm{pH}$ is $\sim 6.8$ or lower, whereas the rates are very low ( $1 \mu \mathrm{m} / \mathrm{yr}$ or lower) when the solution $\mathrm{pH}$ is higher than $\sim 6.8$.

Figure 5 shows the nonuniform corrosion rates versus time from supplementary test 2 . The steady state nonuniform corrosion rates were less than $0.5 \mu \mathrm{m} / \mathrm{yr}$ when the solution $\mathrm{pH}$ was 7.32 or higher, but greater than $30 \mu \mathrm{m} / \mathrm{yr}$ when the solution $\mathrm{pH}$ was 6.96 or lower.

The data from supplementary test 3 are shown in Figure 6 . The data indicate that the steady state nonuniform corrosion (measured after 72-hour immersion) is insignificant ( $<1 \mu \mathrm{m} / \mathrm{yr}$ ) or nearly so

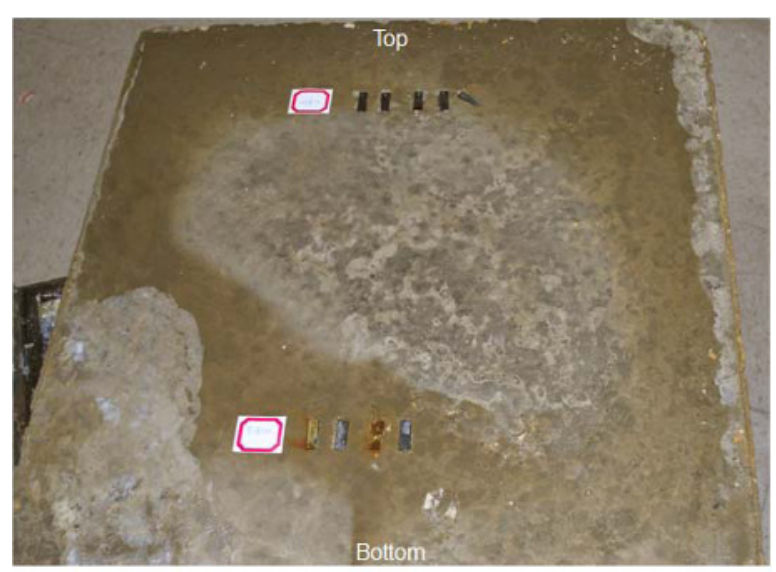

(a)

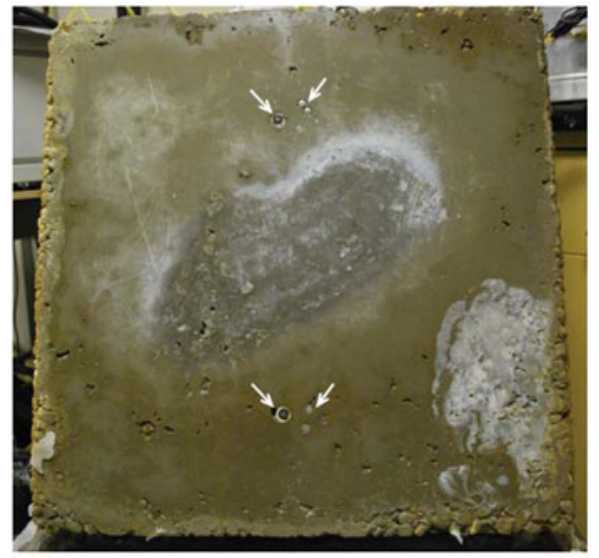

(b)

Fig. 3. (a) Concrete block with rebar coupons after disassembly. (b) Concrete block with CMAS and LPR probes (indicated by arrows) 


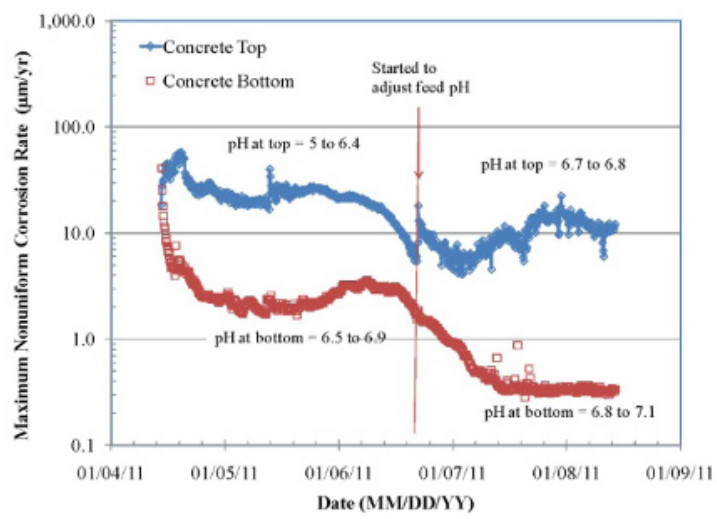

(a)

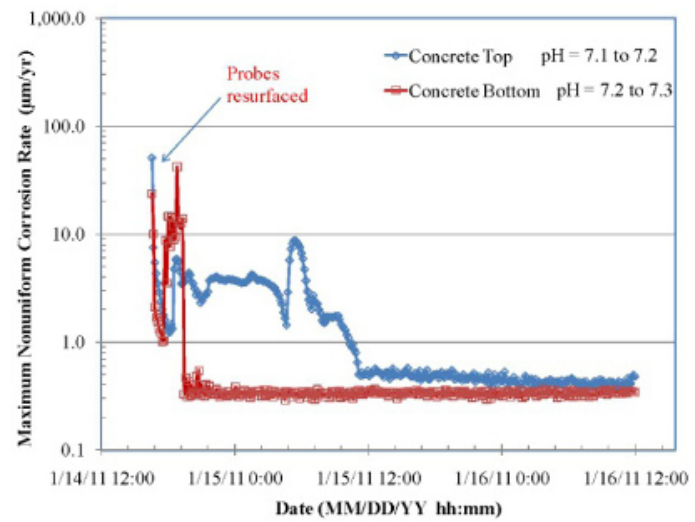

(b)

Fig. 4. Nonuniform corrosion rates versus time measured using CMAS probes near the top (diamond symbols) or near the bottom of an inclined concrete block (square symbols). The ranges in measured $\mathrm{pH}$ of borated water flowing adjacent to the CMAS probes also are indicated. The vertical line in (a) indicates the time when the feed solution $\mathrm{pH}$ was adjusted higher by addition of simulated cement pore solution to the boric acid solution.

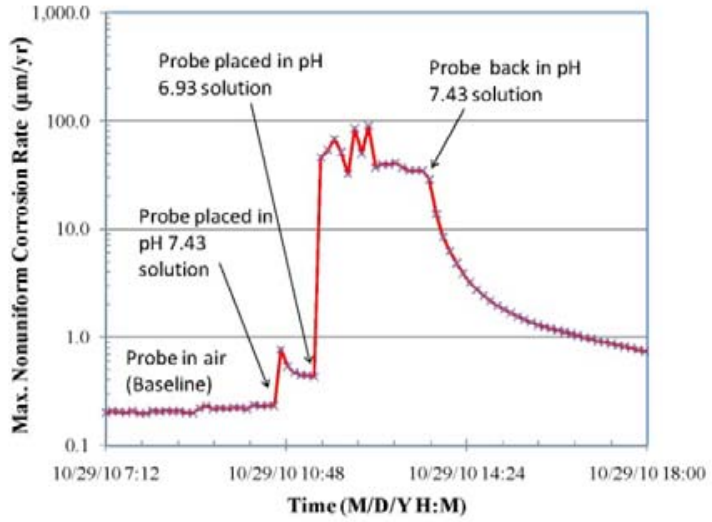

(a)

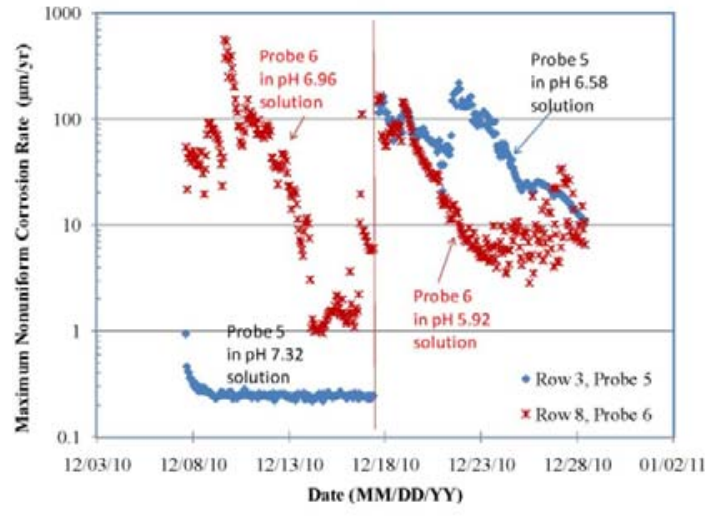

(b)

Fig. 5. Nonuniform corrosion rates measured using CMAS probes immersed (a) in solutions that were collected exiting the concrete block or (b) in several batches of borated water collected exiting the concrete block

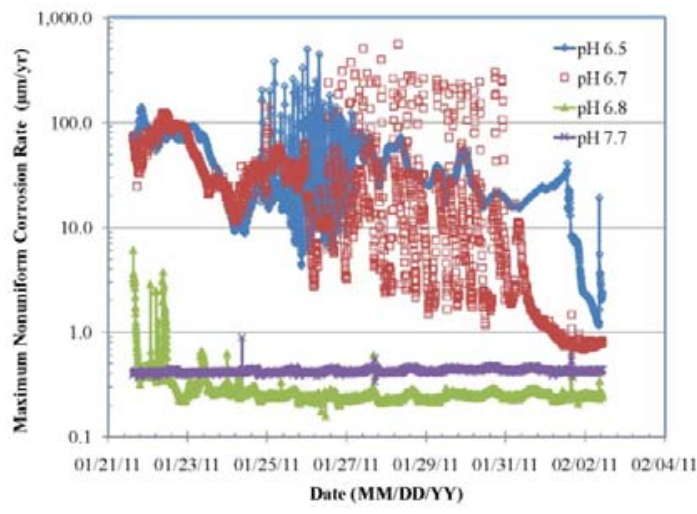

(a)

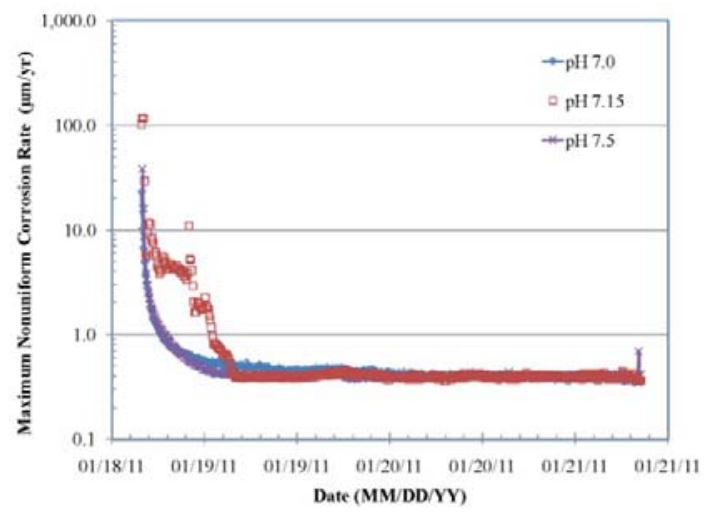

(b)

Fig. 6. Nonuniform corrosion rates versus time measured using a CMAS probe immersed in borated (2,400 ppm B) water with $\mathrm{pH}$ adjusted by adding simulated cement pore solution 
when the $\mathrm{pH}$ was 6.8 or higher, whereas at $\mathrm{pH}$ less than 6.8 the corrosion rate was as high as $\sim 300 \mu \mathrm{m} / \mathrm{yr}$. Data measured over a 2-month period in $\mathrm{pH} 6.0$ and 6.5 solutions, which are shown in Figure 7, indicate that the overall nonuniform corrosion rate decreased over time. However, in contrast to solutions with $\mathrm{pH}$ higher than 6.8, the nonuniform corrosion rates in $\mathrm{pH} 6$ and 6.5 solutions mostly remained in the 3 and $60 \mu \mathrm{m} / \mathrm{yr}$ range, which indicate that the carbon steel in those solutions was not fully passivated even after a 2-month period of immersion in the solutions. In Figure 7, the moving averages of the corrosion rates were plotted to show the trend because the raw data showed fluctuations similar to the data in Figure 6(a) (e.g., pH 6.7 data points). Because the corrosion rates were well above the detection limit of the CMAS probe, the fluctuations in corrosion rate were unlikely to be due to instrument noise. Instead, the fluctuations were likely due to repeated corrosion initiation and repassivation of the sensing surfaces of the CMAS probe electrodes.

\subsection{Threshold pH for rebar corrosion}

Figure 8 plots corrosion rate data versus $\mathrm{pH}$ measured with CMAS probes either (i) in contact with borated water flowing over an inclined concrete surface, (ii) immersed in borated water that was collected exiting the simulated concrete crack, or (iii) immersed in borated water mixed with simulated cement pore solution. The data in Figure 8 were obtained from the nonuniform corrosion rates versus time plots discussed in the preceding section. For better data comparison, the corrosion rates shown in Figure 8 are the measured values $\sim 24$ hours after the freshly polished probes were contacted with or immersed in the solution. Thus, the data represent short-term corrosion rates. Although some differences are evident in the corrosion rates measured from the three tests, the general trend is the same. The corrosion rate is low ( $\sim 1 \mu \mathrm{m} / \mathrm{yr}$ or less) when the solution $\mathrm{pH}$ is $\sim 7.1$ or higher. Below $\mathrm{pH} \sim 7.1$, the corrosion rate increases with decreasing $\mathrm{pH}$ and can reach $\sim 100 \mu \mathrm{m} / \mathrm{yr}$ in solutions with $\mathrm{pH}$ less than $\sim 6.7$. The threshold $\mathrm{pH}$ for carbon steel corrosion in borated solution is between 6.8 and 7.3.

\section{Summary and Conclusions}

Given the uncertainty and lack of sufficient data on the effect of boric acid on rebar corrosion and concrete degradation, experiments were performed to determine this effect. Rebar corrosion rates were measured in boric acid (2,400 ppm B) solution flowing in a simulated concrete crack. The corrosion rates were measured using CMAS and LPR probes and by a rebar coupon weight loss method. Supplementary test methods were used because the test was hampered by flow channeling

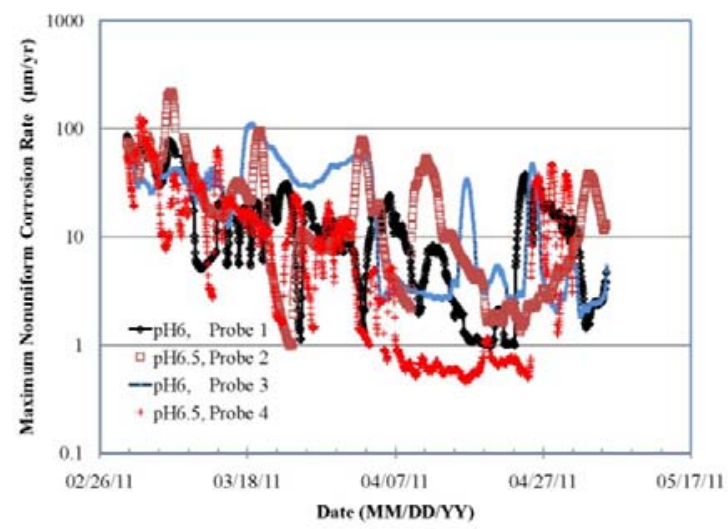

Fig. 7. Moving average of long-term nonuniform corrosion rates versus time measured using CMAS probes immersed in borated (2,400 ppm B) water with $\mathrm{pH}$ adjusted to 6.0 or 6.5 using simulated cement pore solution 


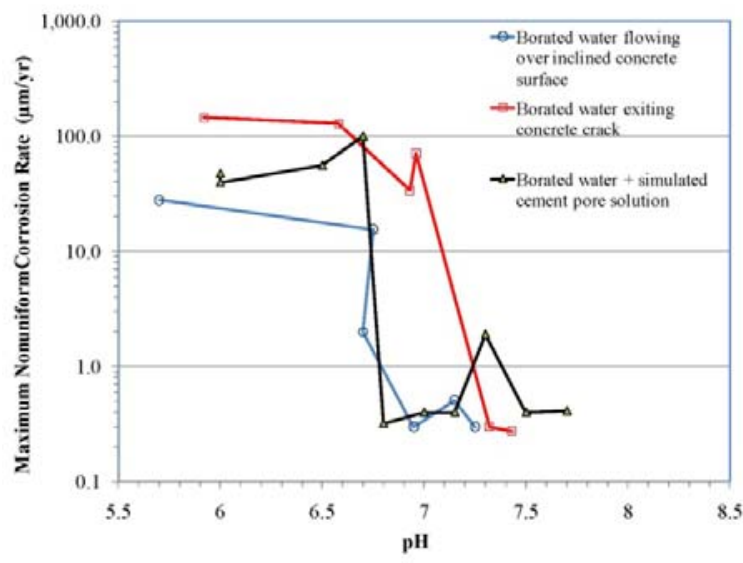

Fig. 8. Summary of nonuniform corrosion rate data from CMAS probes (i) contacting borated (2,400 ppm B) water flowing over inclined concrete surface, (ii) immersed in borated (2,400 ppm B) water exiting simulated concrete crack, and (iii) immersed in borated (2,400 ppm B) water mixed with simulated cement pore solution.

The plotted data are the rates measured $\sim 24$ hours after test initiation using freshly polished probe surfaces.

in the simulated crack. The results indicate that rebar corrosion rates are low ( $\sim 1 \mu \mathrm{m} / \mathrm{yr}$ or less) when the solution $\mathrm{pH}$ is $\sim 7.1$ or higher. Below $\mathrm{pH} \sim 7.1$, the corrosion rate increases with decreasing $\mathrm{pH}$ and can reach $\sim 100 \mu \mathrm{m} / \mathrm{yr}$ in solutions with $\mathrm{pH}$ less than $\sim 6.7$. The threshold $\mathrm{pH}$ for carbon steel corrosion in borated solution is between 6.8 and 7.3.

\section{Acknowledgments}

This paper was prepared to document work performed by the Center for Nuclear Waste Regulatory Analyses $\left(\mathrm{CNWRA}^{\circledR}\right)$ for the U.S. Nuclear Regulatory Commission (NRC) under Contract No. NRC-03-10-066. The activities reported here were performed on behalf of the NRC Office of Reactor Regulation, Division of License Renewal. This paper is an independent product of the CNWRA and does not necessarily reflect the view or regulatory position of NRC.

\section{References}

1. M.R. Fard, Resolution of Generic Safety Issues (U.S. Nuclear Regulatory Commission, Washington, D.C., 2011)

2. R.T. Pabalan, L. Yang, and K.-T. Chiang, Boric Acid Degradation of Reinforced Concrete (Center for Nuclear Waste Regulatory Analyses, San Antonio, Texas, 2011)

3. W. Ramm and M. Biscoping, Nuclear Engineering and Design 179, 191 (1998)

4. X. Jin, N. Jin, and Y. Tian, Key Engineering Materials 400-402, 441 (2009)

5. J.D. Dillard and J.O. Glanville, Composition and Method for Combatting Chloride-Induced Corrosion in Steel in Reinforced Concrete. U.S. Patent Number 5,092,923. Issued March 3, 1992.

6. L. Yang, N. Sridhar, O. Pensado, and D. Dunn, Corrosion 58, 1,004 (2002) 